\title{
Wireless Sensor Network to Monitor Global Warming
}

\author{
Amol N. Patole \\ M.Tech .(Electronics) \\ Department of Electronics and Telecommunication, RIT, Sakharale \\ Dr. J. S. Awati \\ Asst. professor \\ Department of Electronics and Telecommunication, RIT, Sakharale
}

\begin{abstract}
This paper discusses wireless sensor network to monitor global warming \& air pollution. GSM based wireless sensor network is used to monitor global warming parameters such as temperature, humidity, $\mathrm{CO} 2$ and air pollution. Each motes of the wireless sensor network can cover the area wherever GSM network is available. Each mote consists of temperature, humidity, $\mathrm{CO} 2$ and air pollution measuring sensors, equipped with low power consuming GSM module, data logging facility, SD card \& real time clock. Real time clock is used to have exact time stamp of each measurement. SD card is used to store the sensor values locally. Motes can communicate with each other but most of the time they communicate with the central receiver.
\end{abstract}

Keywords - Air pollution, Global warming, GSM, WSN.

\section{INTRODUCTION}

In recent years wireless sensor network gained tremendous attention. All wireless communication is done by wireless sensor network. It has many applications and significance in agricultural, environmental monitoring, home monitoring, habitat monitoring etc. It is possible to monitor global warming with wireless network technology.

In all over world current issue behind extreme climate cycle change, frequently occurring droughts, flood is a global warming. Global warming affects every aspect of nature. Sea level rises and air pollution increases due to global warming. There are much more effect of global warming on living lives.

As all we know global warming is nothing but rise in temperature in climate. Solar radiation from sun is main source of heat energy on earth. Other sources are also there like industrial area, mega cites, nuclear plant and much more. Extra heat energy should be reemitted outside the earth atmosphere. But greenhouse gases hold heat energy within the earth atmosphere. Green houses are $\mathrm{CO} 2, \mathrm{CH} 4, \mathrm{NO} 2$. As green gases increases heat energy increases. Temperature change is observed.

This paper discusses wireless sensor network to monitor global warming \& air pollution.

\section{WIRELESS SENSOR NETWORK DESCRIPTION}

Wireless Sensor Network is developed by connecting each motes with receiver through GSM network. GSM network is already established worldwide so it is easy way to establish a WSN to monitor global warming and air pollution. Each mote that is end node of system consists of atmega 8 microcontroller, sensors, real time clock module, SD card \&GSM module. Temperature sensor, humidity sensor, $\mathrm{CO} 2$ gas sensor and air quality sensor are used in each mote. Real time clock is used to give exact time for each reading. The RTC module provides time \& day, month, year calculations. SD card is used to store all data at end node. If motes does not enough power to transmit the data then SD cards are used to store data at nodes. Later it can be collected manually. 


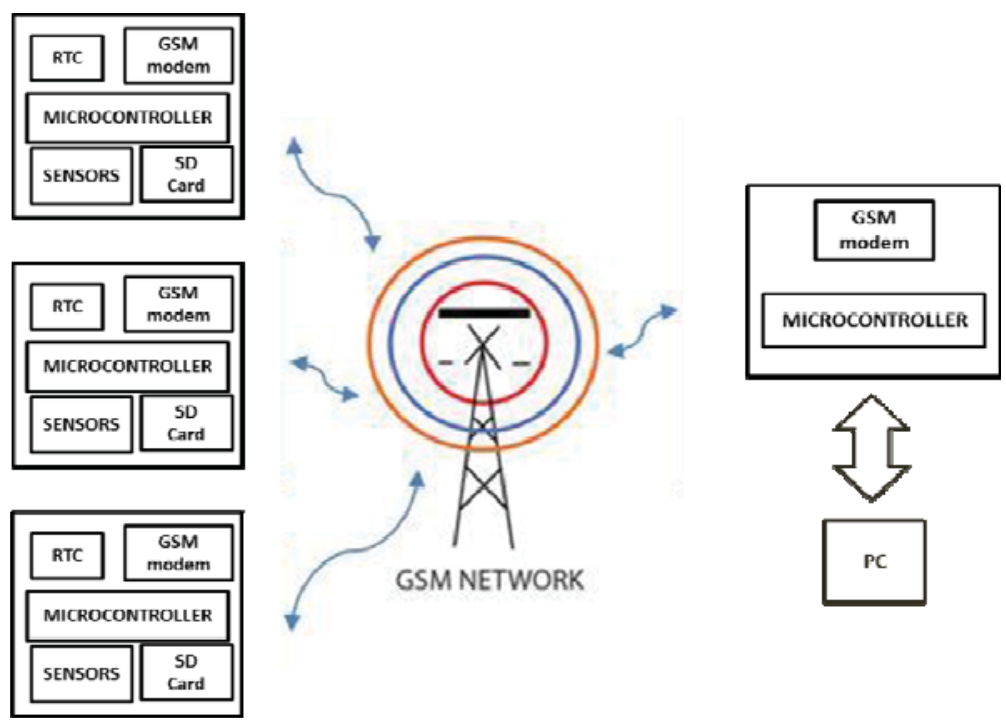

Fig. 1 Block Diagram of System

Heart of each mote is atmega8 microcontroller. It is a small size micro-controller and consumes small amount of power while running in sleep mode. This whole WSN runs on interrupt driven system. After a fixed amount of time interval micro-controller wakes up and collect data from sensors, collect real time stamp, stores data into SD card and then again goes back to sleep. When the time comes to transmit data it wakes up, and sends data to receiver terminal. Receiver terminal is connected with computer. That data get stored into database system or data logger system for further analysis.

\section{III.WIRELESS SENSOR NETWORK DEVELOPMENT}

Wireless nodes consist of Temperature sensor, humidity sensor, $\mathrm{CO}_{2}$ gas sensor and air quality sensor. Sensors and other equipments have been chosen for low power consumption.

Heart of this project is Atmega328 micro-controller. It is a 8 bit Micro controller with RISC architecture. Its speed is up to $16 \mathrm{MIPS}$ throughput at $16 \mathrm{MHz}$. It has $8 \mathrm{~K}$ bytes of flash and 512 bytes EEPROM. Operating voltage $1.8 \mathrm{v}-5.5 \mathrm{v}$, in active mode it consumes only $3.6 \mathrm{~mA} \&$ in sleep mode it consumes less than $1 \mathrm{uA}$ current which made it a perfect choice for this project.

Carbon dioxide sensor MQ7 is used. For standard measurement MQ7 sensitive components require two parts. One is signal output circuit. That can accurately respond changes of surface resistance of the sensor. Second is heating circuit having time control function (high volt. and low volt. work circular). But for this microcontroller circuit is available with sensor.MQ7 has good sensitivity and selectivity to $\mathrm{CO}_{2} \&$ low humidity and temperature dependency. It has long stability which makes it suitable for rough environment.

Metal oxide sensor MQ135 is used. It is made by micro AL2O3 ceramic tube and Tin Dioxide ( $\mathrm{SnO} 2)$ layer. The measurement electrode and heater are placed into a sensitive layer. Measuring electrode and heater are fixed into a outermost shell made by stainless steel and plastic net. The necessary conditions provided by heater. When heater is heated and meets the necessary conditions, the sensor sense the gases. It is used to detect the concentration of volatile gases such as NH3, NOx, alcohol, Benzene, smoke.

DHT11 is capacitive humidity sensor and a thermostat to measure the surrounding air, and output digital values of temperature and humidity to microcontroller.

SD card module is interfaced with microcontroller through SPI interface. A 4GB SD card is used to log data for one year. 
Sim908 has been used as GSM module. SIM908 module is a complete Quad-Band GSM/GPRS module which combines GPS technology for satellite navigation. The compact design which integrated GPRS and GPS in a SMT package will significantly save both time and costs. Power consumption (GSM engine in idle mode) around $77 \mathrm{~mA}$.

RTC module With LIR2032 rechargeable lithium battery is used. About 1 year run time with full BCD clock calendar chip of 56byte non-volatile RAM. The chip can provide second, minute, hour etc information. Built-in power sensor circuit in the chip, with brownout detection and battery switch function. Under battery backup mode, power consumption is below 500uA. It provides accurate calendar up to year 2100 .

Visual basic is used to display all information collected from sensor node through receiver node. It displays data from all three node.

\section{RESULTS}

Transmitter nodes placed at different place. Sensor value transmitted to receiver node as well as displayed on LCD as shown in fig. 2 .

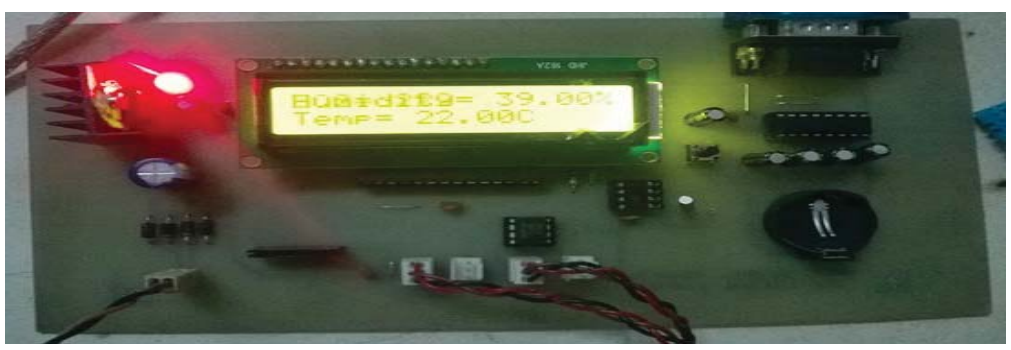

Fig. 2 Transmitter node with LCD display

The data transmitted to the receiver node. At receiver node, we have created a GUI using visual basic. All these sensor data display on the GUI as shown in fig.3.

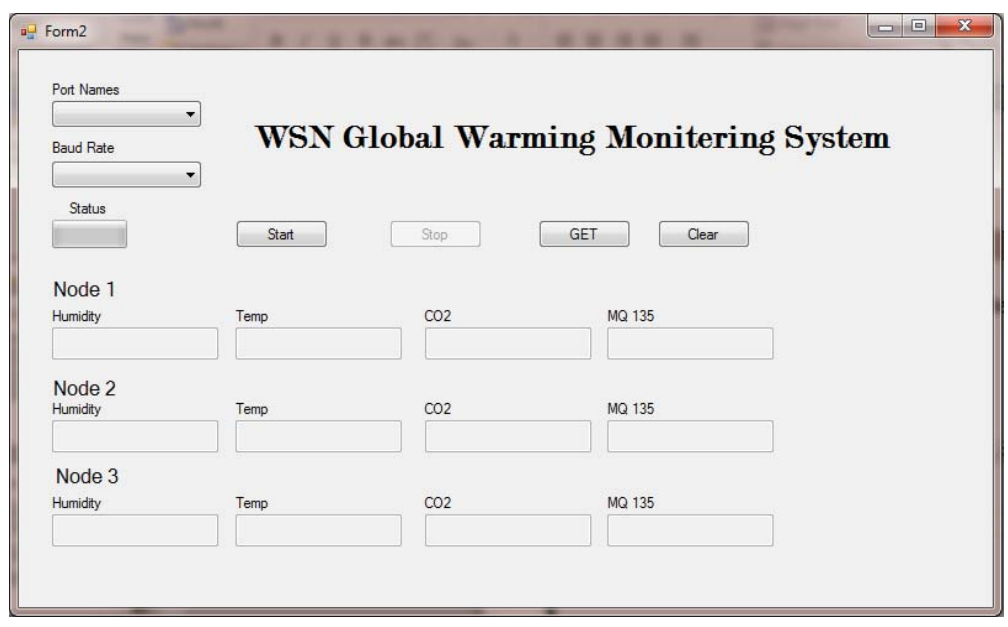

Fig. 3 GUI at Receiver Side

\section{CONCLUSION}

System is developed using atmega328 microcontroller. Temperature \& humidity sensor, $\mathrm{CO}_{2}$ sensor and air quality sensor are used in system. Monitors temperature, humidity, $\mathrm{CO}_{2}$ level and quality of air by means of sensors used. 
Data collected at end node is transmitted to the receiver node where data logging facility is available. Developed system is also useful for environment and air pollution monitoring.

\section{REFERENCES}

[1] Corke, P., Wark, T., Jurdak, R., Hu, W., Valencia, P. and Moore, D., Environmental Wireless Sensor Networks, IEEE Sensors, Vol. 98 , No. 11, pp. 1903-1917, 2010.

[2] Gopala Krishna Moorthy .K, Dr.C.Yaashuwanth, Venkatesh.K.,A Wireless Remote Monitoring of Agriculture Using Zigbee, International Journal of Engineering and Innovative Technology, Vol. 2,pp. 72-74, 2013.

[3] Horst Hell bruck, Max Pagel, Alexander Kroller,Using and Operating Wireless Sensor Network Test beds with WISEBE,10th IFIP Annual Mediterranean Ad Hoc Networking Workshop, pp. 171-178, 2011.

[4] M. Pushpalatha, Revathi Venkataraman, K. Sornalakshmi, T. Ramarao Implementation of Wireless Sensor Network Test BedSRMsenceNet, International Journal of Computer Applications, Vol. 63,pp. 1-4, 2013.

[5] M. Rahmat, M. Azis , E. Rustami , W. Maulina , K.B. Seminar ,H. Alatas, Low Cost Configuration of Data Acquisition System for Wireless Sensor Network, International Journal of Engineering \& Technology, Vol.12,pp. 23-32, 2012.

[6] Muhammad Omer Farooq, Thomas Kunz, Wireless Sensor Networks Test beds and State-of-the-Art Multimedia Sensor Nodes, An International Journal Applied Mathematics \& Information Sciences, 935-940, 2014.

[7] S.Pandikumar, S.P.Kabilan, S.Ambethkar, Architecture of GSM based WSN for Greenhouse Monitoring System in Ambient Intelligence Environment,International Journal of Computer Applications, volume 63-no.6, 2013.

[8] Roy, Somprakash Bandyopadhyay, A Test Bed on Real Time Monitoring of Agriculture Parameters Using Wireless Sensor Networks for Precision Agriculture, ITU Kaleidoscope Academic Conference, 161 - 168, 2009

[9] Dasgupta, Guru Darshan PM, Application of Wireless Sensor Network in Remote Monitoring", First International Conference on Automation, Control, Energy and Systems, pp.1-3,2014.

[10] Vana, Tomislav, Dinko, Marijan kuri and Vendran Bilas,MasliNET: A Wireless Sensor Network based Environmental Monitoring System, MIPRO, Proceedings of the 34th International Convention, Opatija, Croatia, pp. 150-155,2011. 